\title{
Knowledge of Exclusive Breastfeeding and Proposed Infant Feeding Pattern of Post-Natal Mothers in Maiduguri, Nigeria
}

\author{
Kever R. $\mathrm{T}^{1},{ }^{*}$ Dathini $\mathrm{H}^{2}$,Martins S.D. ${ }^{3}$,Inna A.K ${ }^{4}$,Habu $\mathrm{H}^{5}$, \\ Saidu M.A ${ }^{6}$, Gana A.S S $^{7}$ \\ ${ }^{1,2,3,4,5,7 .}$ Department Of Nursing Science, University Of Maiduguri.Nigeria. \\ ${ }^{6}$ Federal Teaching Hospital Gombe
}

\begin{abstract}
Breast milk is known to be the best food for the infants because it contains all the nutrients in the correct proportions. It is readily produced, easily digested and assimilated, has the correct temperature and is always available at no cost. Exclusive breastfeeding protects the child from potentially unsafe food or water. Despite the strong evidence and wide publicity on its benefit, exclusive breastfeeding has remained low in Northern Nigeria. This research therefore is aimed at assessing the knowledge of Exclusive Breastfeeding and proposed infant feeding pattern of post-natal mothers in University of Maiduguri Teaching Hospital. A descriptive survey involving a total of 127 mothers who gave birth to live infants not more than 48 hours were selected using purposive sampling technique, and self-developed questionnaire was administered to collect data from the respondents. Findings revealed that majority of the respondents (70\%) had high knowledge of exclusive breastfeeding, however only few respondents intend to practice exclusive breast feeding. Two-third of the respondents who had received information about EBF got it from health workers. The study therefore suggest that health workers and other government apparatus should intensify efforts that enhances the practice of exclusive breastfeeding.
\end{abstract}

Keywords: Exclusive Breast Feeding, Infant Feeding, Knowledge, Postnatal Mothers.

\section{Introduction}

Breast milk is known to be the best food for the infants because it contains all the nutrients in the correct proportions. It is readily produced, easily digested and assimilated, has the correct temperature and is always available at no cost ${ }^{1}$. Optimal breastfeeding of children has the greatest potential impact on infant's health and development as well as child survival from all preventive diseases to adulthood. Black, Allen, Bhutta, caulfied, De nois, Ezzatic, Mothers and Rivera ${ }^{2}$ reported that optimal breastfeeding of children has the capacity of protecting and preventing 1.4 million deaths in children under five in developing world annually. Traditionally, most mothers keep their babies on breast milk for as long as possible until such a time the child is capable of tolerating traditional foods. This is wise of them since they could not provide replacement of milk and there has usually existed good local knowledge about breastfeeding, although, practices have varied from culture to culture.

Exclusive breastfeeding (EBF) is defined as " infant's consumption of human milk with no supplementation of any type (no water, no juice, no non human milk and no foods) except for vitamins, minerals and medications" ${ }^{\text {"3 }}$. Breastfeeding exclusively does not allow the infant to be exposed to potentially unsafefood or water. Despite the strong evidence and wide publicity on its benefit, exclusive breastfeeding has remained low worldwide. Researchers have unveiled that exclusive breastfeeding pattern have improved significantly in some countries over the past ten years but they are still far from the recommended levels in the developing world as a whole $e^{4,5,6}$. This therefore indicates that the potential to improve child survival in the developing countries remains untapped-only $39 \%$ of all infants 0-5 months of age in developing world are exclusively breastfed $^{7}$

In Nigeria, the major factors influencing exclusive breastfeeding practice includes; urbanization, mothers working outside home, women education, attitudes of health workers, policies of health facilities to exclusively breastfeed or choice of other suitable infant feeding patterns and knowledge of mothers on exclusive breastfeeding pattern among others. Successful breastfeeding depends on mothers' knowledge and beliefs about breastfeeding. Since breastfeeding behaviour of a mother is an important predictor of infant and child nutrition, health and development, it becomes necessary to assess mothers' knowledge, and proposed infants feeding patterns.

\section{Statement oftheProblem}

Global campaign urges mothers to be baby friendly, ${ }^{4,}$ however, in most developing countries of the world like Nigeria, malnutrition is still a life threatening issue particularly among the poor and low income 
earners. The most affected are babies and children under five years of age. High mortality rates are still persisting among the babies who are not breastfed ${ }^{4}$

In Nigeria, despite increasing level of campaign on exclusive breastfeeding, there is still a wide gap between knowledge and practice of breast feeding since most mothers do not appreciate practicing it appropriately ${ }^{8,4}$.As the biblical injunction put it "my people are destroyed due to lack of knowledge". Lack of knowledge and poor practice of Exclusive Breastfeeding may be disastrous to infants and child nutrition, health and development ${ }^{9}$.Therefore this research is aimed at assessing knowledge of Exclusive Breastfeeding and proposed infant feeding pattern of post-natal mothers in University of Maiduguri Teaching Hospital.

\section{Objectives Of The Study}

The specific objectives of this study are to:

Verify the Proposed Infant Feeding Pattern of Post-natal Mothers in University of Maiduguri Teaching Hospital. Ascertain mothers' knowledge about exclusive breastfeeding

Identify mothers' sources of information concerning exclusive breastfeeding.

\section{Null Hypotheses (Ho)}

EBF.

There is no significant relationship between sources of information about EBF and intension to practice

There is no significant relationship between level of Knowledge on EBF and mothers intension to practice EBF

\section{Significance Of The Study}

Findings of this study will add to the existing database and will assist nurses and other health professionals to plan strategies to enhance or sustain exclusive breastfeeding among mothers. If it is found that the mothers practice EBF, they will be encouraged to continue this practice. However, if it is otherwise, they will equally be educated about the advantages of EBF and its positive practices to be maintained in order to enhance the healthy growth of the children.

\section{Study Design}

\section{Methodology}

A descriptive survey design was uses for this study because it deals with the accurate and factual description and summary of the actual situation.

\section{Study Setting}

The research was conducted in Obstetric ward of University of Maiduguri, Teaching Hospital (UMTH) located in Jere local government along Bama road northeastern Nigeria. The hospital which is a tertiary institution has a bed capacity of 530 spread over 20 wards. The hospital serves as referral centre for various individuals seeking tertiary level health care services. Obstetric ward of UMTH has a bed capacity of about twenty four and admits both pre and post-natal cases.

\section{Study Population And Sampling Technique}

Purposive sampling method was used to select 127 mothers who gave birth to live infants not more than 48 hours as respondents for the study.

\section{Instrumentation}

The researchers used questionnaire to collect data from the respondents. The instrument was validated by health experts and ten copies of the questionnaires were pre-tested at state specialist hospital Maiduguri, Borno State using test retest method to ensure consistency and reliability of the instrument. Reliability coefficient of 0.75 was obtained which made it fit for use in the study area. The instrument consisted of three sections; section A was for the demographic data of the respondents, section B elicited responses on the knowledge of exclusive breastfeeding, while section $\mathrm{C}$ dealt with proposed infants and child's feeding pattern.

\section{Procedure ForData Collection}

The researcher obtained an ethical approval from the research and ethical committee of University of Maiduguri, Teaching Hospital. 150 respondents were selected over a period of one week using purposive sampling. Consent was obtained from the pregnant women after explanation of the purpose and objective of the research. The researchers then administered the questionnaires directly to the literate pregnant women, while those that were uneducated, the questions were interpreted for them to choose the right options. Out of the 150 
questionnaires served, only 127 were retrieved. The identities of the women remained anonymous throughout the study period. The questionnaires and responses were treated with confidentiality after retrieval.

Data Analysis

Data collected was analysed manually. Also a marking scheme for the mothers' knowledge on EBF was developed. A correct response was scored as ' 1 ' and incorrect or I don't know response was scored as ' 0 '. The mothers' scores in the section B of the questionnaire were further categorized as high level of knowledge (3-5) and low level of knowledge (0-2). Descriptive statistics of frequency counts and percentages was used to discuss objective one and two while inferential statistics of chi- square was used to test the relationship between independent and dependent variables at $5 \%$ level of significance.

\section{Findings}

Table I: Age of Respondent

\begin{tabular}{|l|l|l|}
\hline Variables & Frequency & Percentage \\
\hline $14-24$ years & 56 & $44.09 \%$ \\
$25-35$ years & 53 & $41.73 \%$ \\
$36-46$ years & 16 & $12.59 \%$ \\
47 and above & 2 & $1.57 \%$ \\
\hline Total & 127 & $100 \%$ \\
\hline
\end{tabular}

TABLE Ishows that respondents from age 14-24 years were the majority with 56(44\%) followed by 25-35years with $53(41 \%)$ then $36-46 y e a r s ~ 16(13 \%)$ and lastly $2 \%$ (2) of the respondents fall within 47 years and above.

Table II: Occupation of the Respondents

\begin{tabular}{|l|l|l|}
\hline Variables & Frequency & Percentage \\
\hline Civil servant & 51 & $40.15 \%$ \\
House wife & 40 & $31.49 \%$ \\
Business women & 18 & $14.17 \%$ \\
Student & 18 & $14.17 \%$ \\
\hline Total & 127 & $100 \%$ \\
\hline
\end{tabular}

TABLE IIshows that $40 \%$ of the respondents were civil servants with the highest score followed by house wives, $31 \%$ and $18 \%$ each of the respondents were both business women and students respectively.

Table III: Educational status of the Respondents

\begin{tabular}{|l|l|l|}
\hline Variables & Frequency & Percentage \\
\hline None/Quranic school & 33 & $25.98 \%$ \\
Primary & 14 & $11.02 \%$ \\
Secondary & 27 & $21.25 \%$ \\
Tertiary & 53 & $41.73 \%$ \\
\hline Total & 127 & $100 \%$ \\
\hline
\end{tabular}

TABLE IIIshows that $41 \%$ of the respondents had tertiary education, $21 \%$ with secondary education. $11 \%$ with primary education and the remaining $25 \%$ have not attained any formal education.

Table IV: Marital status of Respondents

\begin{tabular}{|l|l|l|}
\hline Variables & Frequency & Percentage \\
\hline Single & 2 & 1.57 \\
Married & 91 & 71.65 \\
Widowed & 13 & $10.23 \%$ \\
Divorced & 21 & $16.54 \%$ \\
\hline Total & 127 & $100 \%$ \\
\hline
\end{tabular}

TABLE IVshows that $72 \%$ of respondents were married, $16.54 \%$ divorced, $10.23 \%$ widowed and $1.57 \%$ were single parents.

Table V: Parity of Respondents

\begin{tabular}{|l|l|l|}
\hline Variables & Frequency & Percentage \\
\hline Primipara & 40 & $31.49 \%$ \\
Multipara & 55 & $43.30 \%$ \\
Grand multipara & 32 & $25.19 \%$ \\
\hline Total & 127 & $100 \%$ \\
\hline
\end{tabular}

TABLE Vshows that 55\% of the respondents were multi-parous, $31 \%$ primiparous and $25 \%$ Grand multiparous women. 
Table VI: Booking Statue and Number of Antenatal Visits of the Respondents

\begin{tabular}{|l|l|l|l|l|}
\hline \multirow{2}{*}{ Antenatal visits } & \multicolumn{2}{|l|}{ Mothers booked $\mathrm{n}=100$} & \multicolumn{2}{l|}{ Mothers not booked $\mathrm{n}=27$} \\
\cline { 2 - 5 } & Frequency & Percentage & Frequency & Percentage \\
\hline None & - & - & 27 & $100 \%$ \\
\hline $2-4$ & 50 & $50 \%$ & - & - \\
\hline $5-7$ & 41 & $41 \%$ & - & - \\
\hline Above 7 & 9 & $9 \%$ & & - \\
\hline
\end{tabular}

TABLE VI Shows that out of 100 mothers who were booked, 50\% had 2-4 antenatal visits, 41\% had 5-7 visits and $9 \%$ had above 7 visits. While among the un-booked respondents 27 , none had any antenatal visits.

Table VII:Perinatal Factors of Respondents

\begin{tabular}{|l|l|l|}
\hline Mode of delivery & Frequency & Percentage \\
\hline Spontaneous vaginal delivery & 90 & $70.86 \%$ \\
Operative delivery & 24 & $18.89 \%$ \\
Other assisted delivery & 13 & $10.23 \%$ \\
\hline TOTAL & 127 & $100 \%$ \\
\hline
\end{tabular}

Table VII shows that $90(70.86 \%)$ of respondents had spontaneous vaginal delivery. 18.89\% had operative delivery while the rest $13(10 \%)$ had assisted deliveries.

Table VIII: Knowledge of Respondents about Exclusive Breast Feeding $(n=127)$

\begin{tabular}{|l|l|l|}
\hline Knowledge Areas & Frequency & Percentage \\
\hline Awareness of EBF & 114 & 90.1 \\
Knowledge of what EBF is & 77 & 60.3 \\
Knowledge of when to wean & 25 & 20.0 \\
Knowledge that breast milk alone is sufficient for & 89 & 70.1 \\
the baby for 0-6 months & & \multirow{2}{*}{80.4} \\
Knowledge that more breast milk is produced as the & 102 & \\
baby sucks & & 30 \\
\hline Level of Knowledge & 38 & 70 \\
Low Knowledge(0-2) & 89 & 100 \\
High Knowledge(3-5) & 127 & \\
\hline Total & & \\
\hline
\end{tabular}

TABLE VIIIshows the knowledge of respondents about some aspects of EBF. $90 \%(n=114)$ of respondents were aware of EBF, $77(60.3 \%)$ knew what exclusive breastfeeding is and $(70.1 \% ; n=89)$ knew that breast milk alone is sufficient for the baby for the first six months, $80.4 \%(\mathrm{n}-102)$ knows that more breast is produced as the baby suckles. However, only $(20.0 \% ; n=25)$ knew when to wean the baby. Cumulatively, table 8 also revealed that on a general note; there was high knowledge of EBF $89(70 \%)$ among the respondents.

Table IX: Awareness of Exclusive Breastfeeding and source of Information (n=127)

\begin{tabular}{|l|l|l|}
\hline Sources of information & frequency & percentages \\
\hline Radio & 13 & $10.2 \%$ \\
\hline Television & 16 & $12.60 \%$ \\
\hline Health Workers & 73 & $57.48 \%$ \\
\hline Friends (others) & 25 & $19.69 \%$ \\
\hline Total & 127 & $100 \%$ \\
\hline
\end{tabular}

TABLE IXshows that all of the respondents aware of exclusive breastfeeding. Majority of them (57,48\%) heard it from health workers, $19.69 \%$ from friends and $10.2 \%$ and $12.60 \%$ heard from Radio and television respectively.

Table X: Mothers Choice of Baby Feeding

\begin{tabular}{|l|l|l|}
\hline Choice of feeding & frequency & percentage \\
\hline Mothers' exclusive breast feeding & 51 & $40.2 \%$ \\
\hline Mothers breast feeding and bottle feeding & 74 & $58.3 \%$ \\
\hline bottle feeding only & 2 & $1.5 \%$ \\
\hline TOTAL & 127 & $100 \%$ \\
\hline
\end{tabular}

TABLE Xshows that mothers who intend to exclusively breast feed were 51(40.2\%), mothers who intend to combine breastfeeding and bottle feeding were $74(58 \%)$ while mothers who intend to practice bottle feeding only were $2(2 \%)$.

\section{HYPOTHESES}

Но 1 There is no significant relationship between source of information and mothers' intension to practice exclusive breastfeeding 
Table XI: Relationship Between Sources of Information About EBF and Intension to Practice EBF

$(\mathbf{n}=127)$

\begin{tabular}{|c|c|c|c|}
\hline \multirow[t]{2}{*}{ Sources of Information } & \multicolumn{2}{|c|}{ Intension to Practice EBF } & \multirow[t]{2}{*}{ Total } \\
\hline & YES & & \\
\hline Radio & $7(5.22)$ & $6(7.78)$ & 13 \\
\hline Television & $6(6.43)$ & $10(9.58)$ & 16 \\
\hline Health Workers & $32(29.32)$ & $41(43.69)$ & 73 \\
\hline Friends/Family & $6(10.04)$ & $19(14.96)$ & 25 \\
\hline Total & 51 & 76 & 127 \\
\hline
\end{tabular}

At $5 \%$ level of significance and $\mathrm{df}=3, \mathrm{X}^{2}$ cal of 4.21 is less than $\mathrm{X}_{\text {tab }}^{2}$ of 7.815 . There is therefore no statistical evidence to reject the null hypothesis which states that there is no significant relationship between source of information and mothers' intension to practice exclusive breastfeeding.

$\mathrm{H}_{\mathrm{O}_{2}}$ There is no significant relationship between level of Knowledge on EBF and mothers intension to practice $\mathrm{EBF}$

TableXII: Relationship Between Mothers Level of Knowledge on EBF and Intension to Practice EBF $(\mathbf{n}=127)$.

\begin{tabular}{|l|l|l|l|}
\hline \multirow{2}{*}{ Level of Knowledge on EBF } & \multicolumn{1}{|c|}{ Intension to Practice EBF } & \multirow{2}{*}{ Total } \\
\cline { 2 - 4 } & YES NO & 38 \\
\hline Low(0-2) & $30(15.26)$ & $8(22.74)$ & 89 \\
\hline High(3-5) & $21(35.74)$ & $68(53.26)$ & 127 \\
\hline Total & 51 & 76 & \\
\hline
\end{tabular}

At $5 \%$ level of significance and $\mathrm{df}=1, \mathrm{X}^{2}$ cal of 33.95 is greater than $\mathrm{X}^{2}$ tab of 3.841 . There is therefore a statistical evidence to reject the null hypothesis which states that there is no significant relationship between level of Knowledge on EBF and mothers intension to practice EBF. This implies that mothers' level of knowledge on EBF has a significance influence on their intension to practice EBF.

\section{Socio- Demographic Data Of Respondents}

\section{Discussion Of Findings}

Majority of the respondents were between ages 14 and 24 years, only a few percentage (1.58\%) falls above 47 years. 51(40.15\%) were civil servants and 40(31.49\%) were fulltime housewives. 53(41.73\%) had tertiary education as their highest academic qualification. This result shows that majority of the respondents had formal education and may possibly belong to the working class.

\section{Practice Of Exclusive Breastfeeding}

Among the respondents studied, 51(40\%) intend to exclusively breastfeed their babies while a higher percentage $74(58 \%)$ of respondents intend to combine breast and bottle feeding, only $2 \%$ of respondents intend to bottle feed only. This result is consistent with a study conducted on breastfeeding patterns among mothers in Yobe state, Nigeria where the researcher reported that majority of the respondents $(65.9 \%)$ intend to triangulate breastfeeding and bottle-feeding while only $34.1 \%$ intend to exclusively breastfeed ${ }^{10}$.On the Contrary high level of exclusive breast feeding pattern was reported in other parts of Nigeria,Essien et'al ${ }^{9}$ in Calabar and Raheal, Grace, patience and Bolanle ${ }^{11}$ in Ogun state of Nigeria reported $60 \%$ and $66 \%$ respectively. This implies that the practice of exclusive breastfeeding is low among northern Nigerians than in other parts of Nigeria. This low patronage of exclusive breastfeeding pattern in the northern Nigeria may not be unconnected with the cultural beliefs of many of the ethnic nationalities and mixed feeding promotional practices of breast milk substitute in this part of the country.

\section{Knowledge About Breastfeeding}

Findings also show the knowledge of respondents about some aspects of EBF. 114(90.1\%) of respondents were aware of EBF, $77(60.3 \%)$ knew what exclusive breastfeeding is and $89(70 \%)$ knew that breast milk alone is sufficient for the baby for the first six months. However, only $25(20 \%)$ knew when to wean the baby. Cumulatively, there appears to be a higher knowledge about exclusive among the respondents as revealed by Table 8 . This result supports the aim of the "Baby friendly hospital initiative" which encourages the spread of awareness of exclusive breastfeeding. The high level of awareness on exclusive breastfeeding is supported by $\mathrm{WHO}^{6}$ andRaheal Grace \& Patience and Bolanle ${ }^{11}$. Furthermore, the high level of awareness in this study may be attributed to the efforts made by the health care personnel's in disseminating information on exclusive breastfeeding. Although the hospital was designated as baby friendly, not all hospitals designated as baby friendly carry out activities that leads to successful exclusive breastfeeding. 


\section{Source of Awareness On Breastfeeding}

Out of $113(88.9 \%)$ respondents who were aware of exclusive breastfeeding, $64 \%$ received information from health workers, $22 \%$ from friends and relatives, $5.30 \%$ from Radio and $7.96 \%$ from the television. Results showed that only a few percentages heard about exclusive breastfeeding through the media. This implies that the media in Maiduguri is not effective about information dissemination on the promotion of breastfeeding and hence need to improve on their efforts.

\section{Level Of Knowledge On Breastfeeding And Mothers' Intension To Practice Breastfeeding}

In spite of the high level of knowledge among the respondents, there exists a gap between knowledge and mothers intension to practice EBF. This gap may be partly due to cultural beliefs since exclusive breastfeeding is not among the traditional norms and most of the cultural practices involve giving herbs or traditional medicines in addition to breast milk to babies under 6 month of age. It may also be due to the fact that majority of the mothers fall into the categories of civil servants and house wives (TABLE II), with civil servant carrying the highest percentage. These mothers (working mothers) tend to introduce supplements earlier. This experience has been reported in urban areas like Calabar and Yobe in Nigeria ${ }^{9,}{ }^{10}$. This was in part due to short periods of maternity leaves offered to working mothers by their employers. These mothers tend to breastfeed intensively during their maternity leaves and supplement when they are out for work.

\section{Conclusion}

Majority of the respondents were aware of EBF and knew that breast milk alone is sufficient for the baby for the first six months, yet less than two-thirds of them actually intend to practice EBF. Two-third of the respondents who had received information about EBF got it from health workers.

\section{VII.Recommendations}

- In order to enhance exclusive breastfeeding practices, health workers should intensify their health talks, house visits and communication promoting breastfeeding.

- Hold EBF crusade in the village squares, markets, churches, mosques and gatherings where women usually meet.

- Discourage beliefs, attitudes and practices that do not promote breastfeeding.

- Discourage the use of breast milk substitutes and encourage mothers to breastfeed their babies within one hour of birth.

\section{References}

[1]. Frazer, D.M. \& Cooper, M.A.Myles textbook for midwives, London, Churchill Livingstone, 2003, 14th Edition

[2]. Black R.E, Allen LH, Bhutta ZA, caulfied LE, De nois M, Ezzatic M, Mothers C, Rivera Material and child under nutrition: Global and required exposures and health consequences". The Lancet, Vol. 371,(9608), 2008,243-260.

[3]. Gartner LM, "Breastfeeding and the use of human milk (policy statement) Pediatrics 115 (2), 2005,496-506.

[4]. United Nations and International Children's Education Fund, State of the world's Children.2005 available at www.unicef.org (Accessed on 23 January 2005).

[5]. Nwachukwu, A.E. \&Nwachukwu, A.Common factors responsible for less than six months period of exclusive breastfeeding among women in Nigeria. Journal of International Councilfor Health, Physical Education, Recreation, Sport and Dance (ICHPER-SD), 43(2), 2007, 30-35.

[6]. World Health Organization. Exclusive breastfeeding, 2007.Available at www.whoint/ child-adolescent, (Accessed on 7 February 2007).

[7]. News commentary on exclusive Breastfeedingwww.radionigeria.com, retrieved on 08/08/2014. 7.00am.

[8]. Ene-obong, H.N: Eating right, Calabar, University of Calabar Press,2001

[9]. Essien N., Samson- Akan.P. Ndebbio.T. and John M: knowledge, Attitude, Beliefs and practices concerning exclusive Breastfeeding in Calabar Nigeria. African Journal of Nursing and midwifery volume 2(1),2009, 65-75.

[10] Adeleke, S. I, Kwaghe, B (2005), Breast feeding pattern among mothers in maternity ward of Federal Medical Center, Nguru, Yobe state, Nigeria

[11] Raheal A Grace O, patience A, Bolanle A, Knowledge, Attitude and practice of exclusive breastfeeding among rural mothers in ijebu-ode, Ogun state, Nigeria. West African college of Nursing JournalVol 19 (2), 2008. 